\title{
A BABEL DO FUTURO: POR UMA TRADUÇÃO DA ARCHITECTURE PARLANTE DE METROPOLIS E BLADE RUNNER
}

\author{
Alfredo Suppia $^{1}$
}

\author{
"Vinde! Construamos uma cidade e \\ uma torre cujo ápice penetre nos céus! \\ Façamo-nos um nome e não sejamos \\ dispersos sobre toda a terra!"
}

(Genesis 11, 4)

A arquitetura em Metropolis (1927/2001/2010), de Fritz Lang, e Blade Runner (1982/1991/2008), de Ridley Scott, assume um papel fundamental. Em ambos os filmes, a cidade abandona o caráter de mero palco da ação, tornando-se um componente preponderante da narrativa. Tanto em Metropolis quanto em Blade Runner, a cidade reclama o status de protagonista e personagem onipresente.

Conforme observam Paola Antonelli e Romana Schneider, "Lang dirige uma verdadeira architecture parlante enquanto narradora que se expressa por meio de seus diferentes estilos, formas evocativas a serviço

1 Professor de cinema no Instituto de Artes e Design e no Mestrado em Comunicação da Universidade Federal de Juiz de Fora. 
da ideologia" (1990, p. 76)². O mesmo pode ser dito em relação a Blade Runner. Em ambos os filmes, toda a cenografia, arquitetura ou design de produção suporta discursos suplementares inscritos em formas e estilos. O termo architecture parlante designa o conceito de edificações as quais exprimem ou explicam seu propósito e função por meio de sua própria forma. Surge originalmente com referência ao Neo-classicismo (século XVIII) e à obra de Claude Nicolas Ledoux (1736-1806), sendo depois associado a outros arquitetos do Período Revolucionário, como ÉtienneLouis Boullée (1728-1799) e Jean-Jacques Lequeu (1757-1826), notabilizados pelo geometrismo (principalmente Boullée) e eloquência (especialmente Lequeu, também ilustrador) de seus projetos. A obra mais ambiciosa de Ledoux foram as Salines Royales, projeto incompleto representativo da architecture parlante, localizado em Arc-et-Senans, no departamento de Doubs, a leste na França.

Com a ascensão do modernismo arquitetural da metade do século XX, a architecture parlante cai em desuso, tendo seu interesse posteriormente resgatado pelo pós-modernismo. De modo similar entre si, Metropolis e Blade Runner são filmes que resgatam e reaplicam o conceito de architecture parlante no contexto da arquitetura cinematográfica, valendo-se de formas e estilos manifestos na cenografia como canais suplementares de significação narrativa. Em outras palavras, as formas e estilos que alimentam o design de Metropolis e Blade Runner podem ser tratados como signos suplementares inscritos na diegese, sendo portanto passíveis de uma leitura e interpretação mais detalhadas, até mesmo uma "tradução". Nesse sentido, ambos os filmes estabelecem vínculos entre personagens e seu entorno - por exemplo, em Metropolis, Rotwang (Rudolf Klein-Rogge) e sua casa de linhas expressionistas, evocativa da arquitetura de Hans Poelzig, incrustada na metrópole ultramoderna e geometrizada; em Blade Runner, J. F. Sebastian (William Sanderson) e o Bradbury Building, ou Eldon Tyrell (Joe Turkel) e o mega-edifício em forma de pirâmide pré-colombiana. Em certos momentos, inclusive, aspectos subjetivos dos personagens acabam por reverberar no espaço cenográfico, num procedimento de oblíqua inspiração expressionista - lembremos da sequência do Moloch ou do delírio de Freder (Gustav Fröhlich) em seu quarto em Metropolis.

O filme de Fritz Lang apresenta uma rica confluência de estilos. Patrick McGilligan (1997) faz algumas anotações importantes a respeito

2 "Lang dirige nel ruolo di narratrice uma vera e propria architecture parlante che comunica per mezzo dei suoi stili, pure forme evocative al servizio dell'ideologia." (Antonelli and Schneider, 1990: 76) 


\begin{abstract}
Suppia - 337
da variedade de influências e inspirações plásticas observáveis em Metropolis:
\end{abstract}

\begin{abstract}
Mais de um ensaio tem sido publicado no rastro dos antecedentes poliglotas do design do filme, o qual refletiu em toda a sua violenta diversidade a efervescência artística da Alemanha dos anos 1920. O diretor, embora sua própria carreira como pintor tenha atingido seu pináculo com cartões postais e sketches, demonstrou ampla apreciação de tendências e escolas artísticas contemporâneas - fossem elas o Dada, os surrealistas, a Bauhaus ou os expressionistas. Metropolis seria tão vanguardista quanto Os Nibelungos foi classicalmente estilizado. (...) A influência dos professores da Bauhaus, Lyonel Feininger e Oskar Sclemmer, dos arquitetos Bruno Taut e Hans Poelzig, do escultor Rudolf Belling - cujo estilo figurativo fundia princípios do Cubismo e Futurismo - e mesmo o livre fantasista suíço Paul Klee, todos esses elementos surgiriam em Metropolis. "Nos anos 20 o imaginário expressionista da tecnologia como pesadelo existia lado a lado com o fascínio construtivista pela tecnologia - ambos encontraram seu lugar na arte de vanguarda”, escreveu Heide Schonemann em sua monografia Filmbilder - Vorbilder. "Em Metropolis, também, esse não é um elemento a ser subestimado. A beleza e o horror do mundo da máquina excitou muitos artistas". (1997, pp. 111-2)
\end{abstract}

Embora muitos autores apontem exaustivamente o teor Kitsch do enredo, é no âmbito plástico-fotogênico que Metropolis deslumbra os sentidos, conforme já observara Luis Buñuel, em 1927. Por ocasião da première de Metropolis, no UFA Palast de Berlim, Buñuel escrevera em La Gaceta Literária sua impressão da obra de Fritz Lang, a qual lhe parecia "dois filmes colados pela barriga": "se à história preferirmos o fundo plástico-fotogênico do filme, Metropolis cumulará todos os nossos desejos e maravilhar-nos-á como o mais maravilhoso livro de imagens que algum dia se compôs, como uma arrebatadora sinfonia de movimento" (Buñuel in Rickman, 2004, p. 13). Com efeito, a geometria e a manipulação das massas é admirável no filme de Fritz Lang: grupamentos de trabalhadores formam verdadeiros "organismos" em movimento, geometricamente alinhados e plasticamente transbordantes de significado. Mesmo isoladamente, o homem integra organicamente o cenário. Em Metropolis, a cidade literalmente pulsa e vive. Antonelli e Schneider observam ainda que, no filme de Lang,

Os cubos teatrais nos quais vivem os trabalhadores em multiplicação, serialismo e anonimato, contrasta com a riqueza da Neue Sachlichkeit dos escritórios, com a liberdade rococó dos jardins suspensos e o solipsismo futurista dos prédios populosos da cidade externa. Onde a atmosfera deve tornar-se mística e secreta, como nas catacumbas, na casa de Rothwang ou na catedral, o estilo é o neo-gótico à la Hans Poelzig (1990, p. 76). 
Em resumo, podemos equacionar alguns elementos cenográficos/ arquiteturais comuns a Metropolis e Blade Runner: o hermetismo dos espaços, a verticalidade, a metáfora do labirinto, a referência ao mito da Torre de Babel e a dicotomia arcaísmo x tecnologia - ou gótico x moderno, conforme aponta Tom Gunning em The Films of Fritz Lang: Allegories of Vision and Modernity (200o). Neste breve artigo pretendemos passar em revista cada um desses elementos, considerando-os enquanto canais de comunicação suplementares embutidos nos respectivos "eixos" discursivos de Metropolis e Blade Runner.

Primeiramente, convém lembrarmos que ambos são essencialmente filmes de estúdio, a despeito de algumas locações no filme de Ridley Scott. Por conseqüência da própria filmagem em estúdio e da relevância do décor, os dois filmes apresentam uma atmosfera hermética, espaços bem delimitados e impregnados de sentido.

Metropolis e Blade Runner também são filmes "verticais", e tal verticalidade é aplicada como uma metáfora da hierarquia social e do conflito de classes. Em ambos os filmes, é no interior de algum arranhacéu que ocorre o conflito deflagrador da ação; no caso de Metropolis, a visita de Maria (Brigitte Helm) e suas crianças ao Jardim dos Prazeres e, em Blade Runner, o crime de Leon (Brion James) contra o policial Holden (Morgan Paull). Tanto a personagem Maria, de Metropolis, quanto o personagem Leon, de Blade Runner, são intrusos, indivíduos que invadem um espaço que lhes é vetado, bem acima do nível das ruas. A partir dessa intrusão, ambos os filmes descrevem trajetórias que vão dos subterrâneos ou submundo ao topo dos enormes arranha-céus, santuário das elites ou grandes corporações. A partir daí fica evidente uma organização social que se dá verticalmente, com as classes oprimidas ou desfavorecidas relegadas a níveis inferiores, enquanto as classes dirigentes isolam-se em conforto bem acima da superfície.

Em Metropolis, as classes operárias amontoam-se nos subterrâneos, estendendo-se a geografia social para baixo do nível do solo. A verticalidade em Metropolis, com suas claras implicações sociais, chegou mesmo a ser contestada na época da estréia do filme, como em artigo do The New York Times escrito por H. G. Wells, para quem Metropolis não passava do "mais tolo dos filmes" (Wells apud Elsaesser, 200o, p. 43), uma vez que as tendências urbanísticas da época apontariam uma horizontalização das grandes cidades, com as classes operárias sendo remetidas para a periferia. Thomas Elsaesser detém-se sobre esse aspecto da verticalidade ao comentar que 
O alto-baixo de Lang, rosário de formas arquitetônicas traduzido para a linguagem da luta de classes, não defende nem condena um determinado tipo de construção e suas conseqüências urbanas. Ao contrário, explora o potencial da verticalidade como uma metáfora do poder social de entendimento universal (...). (2000, p. 67)

Elsaesser relembra-nos também de uma crítica de Theodor Heuss, segundo a qual "Lang simplesmente apropriou-se da oposição entre a escada de serviço e a fachada no Kammerspielfilm expressionista, invertendo-a 90o, verticalmente" (Elsaesser, 2000, p. 80).

Em Blade Runner, a metrópole futurista apresenta-se de maneira muito semelhanteà de Fritz Lang, com algumas adaptações. A massa multi-étnica dos que não puderam deixar a Terra rumo às colônias interplanetárias infesta as ruas de Los Angeles, enquanto o mega-empresário e cientista Eldon Tyrell habita o cume de um arranha-céu gigantesco, cujo formato trapezoidal remete às pirâmides Maias ou Astecas. Este arranha-céu é o prédio da Tyrell Corporation, o qual constitui uma metáfora bastante explícita da hierarquia social. É do topo deste edifício que o milionário Tyrell especula financeiramente e administra seu império, a exemplo de Joh Fredersen (Alfred Abel), que administra a cidade do alto da Moderna Torre de Babel no filme de Fritz Lang. Assim como em Metropolis, em Blade Runner também percebemos três diferentes níveis espaciais de ação - subterrâneos, superfície e topo dos edifícios. Em ambos os filmes, é no topo das edificações - telhado da Catedral, em Metropolis, cobertura do Bradburry Building, em Blade Runner - que ocorrem as seqüências de desenlace.

Notemos que o filme de Ridley Scott apropria-se da verticalidade como metáfora da estratificação e hierarquia sociais, bem como do conflito de classes, seguindo um padrão inaugurado no Metropolis de Lang. ${ }^{3}$ Devemos observar também que, tanto em Metropolis quanto em Blade Runner, a verticalidade assume o caráter de crítica social ao mesmo tempo em que se refere a mitos antigos, narrativas bíblicas ou metarrelatos de inspiração religiosa. O filme de Fritz Lang está fortemente impregnado do imaginário cristão, no qual constatamos referências explícitas ao "Céu" e à "Terra", ao "Éden" - transfigurado no Jardim Eterno dos Prazeres -, bem como ao mito de Adão e Eva, representado pelos personagens Freder e Maria. Embora de forma diferenciada, Blade Runner retoma esse imaginário cristão em

3 Com um pequeno diferencial: embora o filme de Scott despreze os subterrâneos, as verdadeiras elites não habitam meramente o topo dos arranha-céus, mas sim as colônias interplanetárias, bilhões de quilômetros além do solo terrestre. 
sua metrópole futurista, na qual o andróide busca obstinadamente seu "Criador", no intuito de obter a indeterminação sobre sua mortalidade. Em ambos os filmes, os protagonistas - Freder em Metropolis, Deckard em Blade Runner - percorrem trajetórias que podem ser comparada à catábase órfica, a descida aos infernos e o retorno revelador.

Além da verticalidade como metáfora, também a metáfora do labirinto procede como algo comum a Metropolis e Blade Runner. A descrição das respectivas cidades de ambos os filmes “(...) faz reverberar na metrópole moderna as conotações do labirinto mítico: a perplexidade e o assombro, a complicação do plano e a dificuldade do percurso" (Gomes, 2008, p. 63). Freder explora os subterrâneos e perambula pelas ruas em busca de Maria, tentando destrinchar a incompreensível "mecânica" da cidade dirigida por seu pai; Deckard (Harrison Ford) cruza o ar em spinners ou persegue por ruas claustrofóbicas e apinhadas de gente os replicantes rebelados. Vistas do alto, as cidades de Metropolis e Blade Runner são "labirintos de torres". No nível das ruas, o hermetismo domina a atmosfera por entre as paredes de concreto. E o caráter labiríntico das cidades de ambos os filmes é também acirrado pela poluição visual proveniente da abundância de signos arquitetônicos e de massa. Tanto em Metropolis quanto em Blade Runner a publicidade se faz presente em diversos espaços urbanos e, no filme de Scott, isso é ainda mais acentuado.

Fredric Jameson (1997) e outros autores referem-se à metrópole pósmoderna como uma cidade fragmentada, impossível de ser traduzida num mapa geográfico perfeitamente organizado. Nessa cidade, o indivíduo tem a noção fragmentada de sua localização e dos caminhos que deve trilhar no intuito de chegar a determinado local. Contudo, a noção do todo lhe é impossível, dada a multiplicidade e constante mutação da paisagem e do panorama urbanos, o que acarreta uma espécie de deriva referencial. Esse sintoma deve ser relacionado, num certo nível, aos processos de conurbação. Ferreira Gullar ilustra o gigantismo mutante e a impossibilidade de uma totalidade sensível da metrópole pós-moderna na "Ufu" de seu Cidades Inventadas (1997, pp. 7-11), em que a cidade é algo interminável e, quando e se é que ela termina, imediatamente liga-se a outra, e mais outra, e mais outra, numa inesgotável paisagem urbana que remete, também, ao mito grego do labirinto de Dédalo.

No contexto da verticalidade e do labirinto, emerge como metáfora central em ambos os filmes o mito da Torre de Babel. Nesse sentido, tanto Metropolis quanto Blade Runner podem ser vistos como épicos futuristas do mito babélico. Em ambos os filmes temos o equivalente figurativo da Torre de Babel nas principais edificações das metrópoles futuristas. Essa 
referência iconográfica é relevante e devemos atentar para o que afirma Renato Cordeiro Gomes em relação ao mito babélico na literatura:

\begin{abstract}
Sendo, ao mesmo tempo, imagem da construção interminável, do desejo eterno, e da ruína e da devastação nelas já inscritas, a Torre passa a ser um dos emblemas da megalópole: a cidade babélica. (...) E ainda mais: pode-se marcá-la com o símbolo da intensidade vertical da cidade como celebração da tecnologia. (2008, p. 88)
\end{abstract}

Em Lang, o conflito de classes ganha equivalente figurativo na construção da torre grandiosa, e uma seqüência memorável do filme não por acaso é dedicada inteiramente à narração do mito. Conforme apontam Lotte Eisner (1986) e Dietrich Neumann (1999), a Torre de Babel em Metropolis inspira-se na famosa pintura de Pieter Bruegel, de 1563 (Cf. Neumann, 1999, p. 96). ${ }^{4}$

Segundo Ismail Xavier (2007), o mito de Babel em Metropolis significa bem mais do que a simples referência à monumentalidade vertical da cidade. Trata-se de uma parábola no seio de outra parábola, que ilustra em detalhes os termos de uma analogia entre o futuro e o passado mítico. Para o autor,

Há um jogo de espelhos pelo qual a lenda de Babel forma uma versão reduzida do relato maior que dá conta dos fatos em Metropolis, para que a analogia se faça uma quase identidade, uma repetição que o filme trabalha de modo particular, solo para que a mesma frase edificante arremate a pregação, aqui e no final do filme. (Xavier, 2007, pp. 22-3)

A lenda da torre conforma-se, assim, num emblema dos discursos relativos à monumentalidade e aparência, organização social, divisão do trabalho e relações de poder, presentes ao longo de toda a narrativa. A seqüência dedicada à narração do mito babélico em Metropolis constitui "uma história dentro da história", e é apontada por Tom Gunning como um "texto tutorial" para a plena leitura das alegorias no filme de Fritz Lang (Gunning, 2000, p. 56). Tal seqüência é visualmente muito rica, repleta de referências simbólicas - por exemplo, as cinco colunas convergentes de trabalhadores, configurando uma mão espalmada. De acordo com Gunning,

A escolha da Torre de Babel como uma alegoria para essa nova linguagem universal do cinema mudo revela a tensão no âmago da alegoria de Lang (...)

4 Outra tela, "A Torre de Babel” do pintor renascentista holandês Lucas van Valckenborg, também pode ser cogitada. 
a releitura da Torre de Babel de von Harbou tem um certo poder, localizando a origem da dispersão da humanidade não no ciúme divino, mas na falência da unidade do trabalho, e assim da linguagem. Entretanto, os limites da idéia política de Harbou são também naturalizados por sua alegoria: a divisão do trabalho não é questionada, nem as relações de poder inerentes a ela reveladas. Ao invés, é "natural" que as "mãos" e os "cérebros" tenham diferentes funções. O único problema é de comunicação. (2000, p. 56-7)

Percebemos, portanto, que o imaginário de Babel orienta diretamente a narrativa de Metropolis, o mito manifesto numa sequência explícita em particular, num componente principal do cenári (a Torre de Babel Moderna), e diluído ao longo de toda a fábula. Os primeiros sketches de Erich Kettelhut, set designer de Metropolis, previam a Catedral Gótica como edificação central e dominante do cenário, numa alusão à resistência do antigo em meio ao progresso tecnológico. No entanto, Lang chegou mesmo a riscar o esboço da catedral no primeiro sketch de Kettelhut, solicitando ao desenhista que a substituisse pela "Torre de Babel Moderna". ${ }^{5}$ A partir daí, Kettelhut esboçou outros cenários, num dos quais a edificação central dispunha de um gigantesco platô, sobre o qual funcionava um aeroporto. Só depois veio a versão definitiva, finalmente aprovada por Lang, com o edifício monumental ao centro, de onde o capitalista Joh Fredersen dominaria toda a cidade. A propósito, a concepção de Lang da metrópole do futuro ia de certa maneira ao encontro de algumas discussões arquitetônicas da época, dentre as quais a do arranha-céu alemão como símbolo de pujança, espécie de "coroa da cidade" (Stadtkrone), ao redor da qual se organizaria toda a moderna metrópole alemã. Conforme afirma Dietrich Neumann, “(...) As silhuetas das cidades do futuro, que muitos arquitetos discutiam naquele tempo, deveriam ser dominadas não por torres de igrejas, mas por modernos "templos de trabalho": os arranha-céus" (1999, p. 96). Neumann atenta também para o fato de que,

Kettelhut deu muita atenção à torre no fundo, finalmente dando-lhe uma forma monumental e ameaçadora. Essa transformação parece ter sido um reflexo do debate na Alemanha. As formas massivas das estruturas monumentais usualmente citadas nesse contexto despertaram as memórias do imperialismo germânico, e, curiosamente, Metropolis foi celebrado como uma demonstração de poder nacional. Entretanto, a cena final da reconciliação entre o governante

5 Na produção dos cenários, Lang referia-se ao edifício central do filme como se este fosse realmente uma citação da Torre. No romance de Thea Von Harbou, roteirista de Metropolis, o mesmo edifício, onde se situa o escritório de Joh Fredersen, é de fato denominado "Moderna Torre de Babel". 
e os oprimidos tem lugar na escadaria da catedral. O papel da catedral como coração de Metropolis, descartado no primeiro esboço de Kettelhut, foi restaurado. (1999, pp. 97-8)

Em Blade Runner, a metáfora da Torre de Babel não é tão explícita quanto em Metropolis, embora também se manifeste como um subtexto. A Los Angeles de 2019 é a própria Babel pós-moderna, superpopulosa e multifacetada culturalmente, haja vista o idioma sincrético praticado pelos populares. A costa oeste dos Estados Unidos apresenta-se quase como uma colônia oriental, dado o poder de penetração das corporações japonesas na economia norte-americana. Assim como em Metropolis, vem à tona a temática da luta de classes: o operário escravizado do filme de Lang dá lugar ao trabalhador geneticamente projetado. A Los Angeles high tech é uma referência bastante explícita à Babel mítica: a acirrada diversidade cultural, a incomunicabilidade, a monumentalidade, o apogeu tecnológico, húbris e ruína - todos esses elementos podem ser observados na megalópole de Ridley Scott. Além disso, também veremos em Blade Runner um equivalente figurativo da Torre de Babel no próprio cenário: a sede da Tyrell Corporation. As mega-pirâmides gêmeas dominam a paisagem e, no topo de uma delas, habita o gênio capitalista Eldon Tyrell, alheio à poluição e parafernália das ruas. Tyrell é o "Criador" dos Nexus-6, a quem Roy Batty (Rutger Hauer) irá recorrer em sua busca de mais vida. Na seqüência em que "Criador" e "criatura" se encontram, no topo da Tyrell Corp., observamos uma clara citação a um misto de imaginário pagão e cristão no filme de Ridley Scott. O mito de Prometeu e sua releitura cristã ditam a atmosfera da "sequência do parricídio" e da "queda do anjo portador da luz".

Em sua análise da "alegoria langiana" e investigação do mito de Babel como "texto-tutorial" para a devida leitura do discurso simbólico em Metropolis, Ismail Xavier apresenta da seguinte forma o mosaico de citações míticas do filme de Lang:

A lógica que marca a progressão da intriga incorpora motivos narrativos da teia dos mitos que incorpora. Há o encontro do herói com a personificação da morte, a descida aos infernos, a ameaça do dilúvio, a imitação de Cristo, o auto-da-fé. Combinando a causalidade mágica, as metamorfoses e um enredo apoiado no paradigma da batalha entre princípios (Bem e Mal, Vícios e Virtudes), o filme encena um drama vivido por "agentes daemônicos" e inscreve a sua narrativa numa forma canônica do alegórico herdada da Idade Média, conforme os termos cunhados por Angus Fletcher. Em consonância, cada personagem se associa a um espaço simbólico da cidade, e a composição das cidades reserva a cada agente os atributos que marcam sua pertinência a uma "ordem cósmica", hierarquia dos seres que se expressa nas aparências. 
Passamos, assim, de um primado da ordem mecânica para o da organicidade, e não surpreende que a parábola moral se enuncie na fórmula que adota a sintaxe do corpo - "o coração deve ser o mediador entre o cérebro e as mãos" - como modelo para a sociedade. Do mesmo modo, não surpreende que, na luta final, o badalar dos sinos da Catedral venha cumprir o seu papel de advertência que leva à salvação da boa Maria das mãos de Rotwang e à vitória do Bem. Esta, não por acaso, é celebrada na praça que condensa os resíduos da ordem espiritual da Idade Média na cidade-máquina do futuro, ponto final da fábula que traz a Catedral ao centro e redime Metropolis de sua vocação ao desastre. (Xavier, 2007, p. 21)

Guardadas as devidas proporções, a mesma análise de Xavier poderia ser aplicada a Blade Runner. Neste filme também há "o encontro do herói com a personificação da morte" (Leon), "a descida aos infernos" (perseguições e revelações no nível das ruas), "a ameaça do dilúvio” (chove ininterruptamente na Los Angeles do futuro), "a imitação de Cristo" (Roy Batty; Deckard), “o auto-da-fé”. Conforme aponta Xavier em relação a Metropolis (2007, p. 21), também em Blade Runner "cada personagem se associa a um espaço simbólico da cidade, e a composição das cidades reserva a cada agente os atributos que marcam sua pertinência a uma 'ordem cósmica', hierarquia dos seres que se expressa nas aparências". Lembremos de J. F. Sebastian e do Bradbury Building, de Eldon Tyrell e o mega-edifício piramidal.

Outro aspecto fundamental em ambos os filmes, que emerge relacionado aos questionamentos de ordem política e social, é o embate arcaísmo x tecnologia, o qual se torna evidente já no âmbito da arquitetura das metrópoles. Como Neumann aponta:

Ecoando o famoso veredito de H.G. Wells sobre Metropolis, de Fritz Lang - em vez de 100 anos à frente, ele considerou o filme um terço de século ultrapassado - Ridley Scott queria um "filme ambientado 40 anos à frente, ao estilo de 40 anos atrás” (Ostrow, 1981). Essa premissa não é a única conexão com Metropolis, para o qual Blade Runner deve muito em termos de idéias para cenários e imagem da cidade. Acima de tudo, Blade Runner mostra uma cidade com história, com edifícios que têm estado ali por muito tempo e têm sobrevivido sob modernos arranha-céus gargantuescos. Em Metropolis, esses sobreviventes eram a catedral, a casa do inventor e as antigas catacumbas. Na Los Angeles decadente do futuro, encontramos o Yukon Hotel, a Union Station (1931-39), o Bradburry Building (1893) e a Ennis Brown House (1923), de Frank Lloyd Wright. (...) Um conceito-chave para o design da cidade foi o do "retrofitting" ou "layering" - a contínua reparação e adaptação para novas necessidades, que levam à imagem atraente de edifícios recobertos por uma rede de dutos, encanamentos e restos tecnológicos. (1999, pp. 151-2) 
A propósito, em Blade Runner podemos reconhecer no próprio personagem de J. F. Sebastian uma metáfora desse embate arcaísmo $\mathrm{x}$ tecnologia: vivendo no Bradburry's Building, edifício centenário, o engenheiro genético reúne em seu apartamento objetos antigos ou anacrônicos; embora projete a quintessência da tecnologia (os andróides Nexus 6), sofre da "síndrome de Matusalém", doença que lhe confere saúde e aparência quinquagenárias, a despeito de seus 25 anos. Ao mencionar que "O homem que cria os andróides - Rothwang em Metropolis, Sebastian em Blade Runner - são os personagens mais profundamente enraizados na história, os que vivem em prédios antigos (...)", Dietrich Neumann (1999, p. 152) situa-os como personagens-chave na compreensão do embate arcaísmo $\mathrm{x}$ tecnologia proposto em ambos os filmes.

Em Metropolis, tal embate tornou-se aspecto amplamente discutido por críticos e teóricos, exaltado por alguns como o discurso fundamental do filme, em detrimento da ideologia "fracassada" do entendimento trabalho-capital na metáfora do "coração como mediador". O próprio Lang teria apontado como desenvolveu com relevância o tema do embate entre as esferas mística e tecnológica ao longo das filmagens, ao mesmo tempo em que já exprimia descontentamento com o rumo ideológico pelo qual a narrativa evoluía. Já em Blade Runner, o embate arcaísmo $\mathrm{x}$ tecnologia ganha nuances pós-modernas mais evidentes; em vez de superfícies limpas, geométricas e de ângulos acurados, a constante readaptação das edificações a novas funções pode ser evidenciada nas visíveis "camadas" (layering) e "reconstruções" (retrofitting) observadas por Neumann (1999). Tal constatação configura um argumento de reforço à noção do embate arcaísmo x tecnologia no filme de Scott, uma vez que todo objeto ou edificação, por mais antigo que seja, é readaptado a funções contemporâneas (inclusive os spinners, os veículos voadores, causam essa impressão). Ainda sobre esse assunto, Neumann retoma declarações de Lawrence G. Paull, designer de produção de Blade Runner:

\footnotetext{
Para o edifício que fizemos, eu trouxe todas as fotografias de Milão, e tiramos fotografias das arcadas, colunas, coisas clássicas, e toda a arquitetura. (...) fomos do Egípcio ao Déco, do ultramoderno ao Clássico, de Frank Lloyd Wright a Antonio Gaudí. Nós virávamos as fotografias de lado, de cima para baixo, do avesso, e a partir dessas experiências chegamos a uma rua que mais parecia ter sido tirada de Conan, O Bárbaro, em 2020. (...) Eu não queria ângulos retos; eu não queria superfícies lisas (Lawrence G. Paull, 1992). (Neumann, 1999, p. 152)
}

A estética pretendida por Paull e Scott encontra uma matriz no próprio Metropolis de Fritz Lang. De acordo com Thomas Elsaesser, 
Cerca de 6o anos depois, Metropolis ganha o status de um Ur-text da pósmodernidade cinemática, a epítome de uma sensibilidade que seus autores provavemente teriam reprovado: o techno-kitsch retrô, e portanto o arquétipo de um gênero cinematográfico que eles não poderiam imaginar, o filme desastre de ficção científica noir. (2000, p. 7)

Por fim, vale a pena destacar o papel da monumentalidade como comentário auto-referente, metatexto de propaganda de cinematografias industrialmente poderosas. Metropolis, superprodução da UFA, pretendia coroar um período de excelência artística e comercial do cinema alemão. Não surpreende que tenha se tratado de um épico futurista, protótipo do gênero que atualmente conhecemos como ficção científica. Por décadas a ficção científica cinematográfica tem servido como estandarte da indústria audiovisual hegemônica, supostamente a única detentora de know-how e recursos para atender às demandas do gênero. Parece ao mesmo tempo conveniente e irônico, portanto, que nos anos 1920 Metropolis tenha abraçado a metáfora do mito babélico, uma empresa divina, e que a superprodução da UFA, a exemplo da Torre de Babel, tenha se revelado um empreendimento comercialmente ruinoso. Em sua análise de Metropolis, Ismail Xavier observa que

A pauta do debate e ambição do projeto fizeram da arquitetura o princípio maior de unidade da representação, atando o impulso alegórico ao monumental. Se o gênero "grande espetáculo" favorece tal ligação. Esta aqui se aprofundou de modo a produzir uma convergência entre o conteúdo da representação e o mode de fabricá-la. Há a primazia da cidade-monumento sobre a cidadehabitat, e a tematização da técnica como elemento estruturante do universo urbano localizado no futuro implica na exibição da técnica do cinema como competência de simulação de tal universo. O filme constrói, na tela, uma cidade imaginária e, ao mesmo tempo, fala de si mesmo como força de composição de tal espaço com teor totalizante. Há, nessa composição, uma alegoria do próprio cinema, e sua dimensão mais interessante vem exatamente dessa ambivalência da forma, pois há contradição entre o impulso questionador - seja da hipertrofia da técnica ou da relação fetichista com a arquitetura - e o fato de que é de tais excessos que o filme retira o próprio princípio de sua encenação. (2007, pp. 33-4)

Xavier acrescenta que, "[a]o incorporar Babel como uma chave de codificação do seu discurso sobre o moderno, Metropolis faz um movimento inevitavelmente reflexivo, pois inscreve a sim mesmo na questão que privilegia." (2007, p. 34). O autor compara o filme de Lang a outras "superproduções", como Cabiria (1914), de Giovanne Pastrone, ou Intolerância (1916), de D. W. Griffith, filmes nos quais “(...) a busca do 
espetacular envolve um diálogo com espaços arquitetônicos em grande escala" (Xavier, 2007, p. 34), para concluir que,

\begin{abstract}
Embora não contemporâneos, esses filmes de Griffith e Lang são dois exemplos extraídos de um contexto histórico que, desde o início do século até a Segunda Guerra, se definiu por uma competição acirrada, esforço de hegemonia nos mercados e exacerbação dos nacionalismos que transformou as Exposições Universais, ponto de celebração do progresso, em terreno de rivalidades entre os países da Europa e os Estados Unidos. Esse quadro deixou sua marca no campo da produção cinematográfica, notadamente no caso de projetos de grande investimento que se postaram como emblemas de uma competência técnica nacional disposta a ter a sua voz na definição dos caminhos do cinema. Os filmes em questão constituem dois projetos tipicamente babélicos, em termos da saga da produção, do resultado monumental e do desastre financeiro. Enquanto projetos explícitos de exibição de uma força, eles mostram muito bem o contexto de competição em que se insere esse impulso em direção ao monumento enquanto afirmação de uma identidade, construção de uma imagem desejável." (Xavier, 2007, p. 34)
\end{abstract}

Nos anos 1980, Blade Runner talvez não tivesse a mesma pretensão que Metropolis. Tratava-se de um filme com orçamento moderado para os padrões de primeira linha de Hollywood, não de um blockbuster emergente. Mesmo assim, o filme de Ridley Scott estourou o orçamento previsto. Contudo, graças também a uma feliz coincidência de talentos e motivações, Blade Runner acabou contribuindo à sua maneira para a noção popular de que "é em Hollywood que se faz cinema de ficção científica". Pelo menos desde Metropolis o cinema de ficção científica tem sido utilizado como vitrine de exibição da expertise e recursos da indústria audiovisual.

Conforme pudemos observar neste breve estudo, a cidade, enquanto palco das relações sociais, tem papel crucial na cinematografia de ficção científica esua "poética dosespaços", desdeo período mudo. Depositáriadas expectativas e temores do homem face ao progresso científico e industrial, a cidade da ficção científica no cinema é uma verdadeira obsessão: ela é síntese da condição humana, para o bem ou para o mal. Isso é o que ocorre exemplarmente em Metropolis e Blade Runner, filmes nos quais emerge um personagem comum, onipresente e que abarca organicamente todos os demais: a grande metrópole futurista. A cidade de Fritz Lang, cabe lembrar, é caudatária de uma forte "arquitetura imaginária alemã”. Já a Los Angeles de Ridley Scott é o amálgama de diversas paisagens urbanas, culturais e temporais. O diretor, que afirmara ser algumas vezes o design a própria mensagem, imprimiu um caráter multifacetado e até mesmo 
fractal à sua metrópole do futuro. A cidade de Blade Runner é ora Los Angeles, ora Nova York, ora Tóquio, ora a Metropolis de Fritz Lang.

\section{REFERÊNCIAS BIBLIOGRÁFICAS}

ANTONELLI, Paola e SCHNEIDER, Romana. “Metropolis in vitro”, in Domus, no 717 , junho 1990.

BUÑUEL, Luis. “Metropolis (1927)”. In: Gregg Rickman (ed.), The Science Fiction Film Reader. New York: Limelight, 2004, pp. 13-5.

EISNER, Lotte. Fritz Lang. New York: Da Capo, 1986.

ELSAESSER, Thomas. Metropolis. London: BFI, 2000.

GOMES, Renato Cordeiro. Todas as Cidades, A Cidade. Rio de Janeiro: Rocco, 20o8, 2ª ed.

GULLAR, Ferreira. Cidades Inventadas. Rio de Janeiro: José Olympio, 1997.

GUNNING, Tom. The Films of Fritz Lang: Allegories of Vision and Modernity. London: BFI, 2000.

JAMESON, Fredric. Pós-Modernismo: A Lógica Cultural do Capitalismo Tardio. São Paulo: Ática, 1997.

NEUMANN, Dietrich. Film Architecture: Set Designs from Metropolis to Blade Runner. Munich: Prestel, 1999.

WELLS, H. G. "Mr. Wells reviews a current film: He takes issue with this German conception of what the city of one hundred years hence will be like". In: Gregg Rickman (ed.), The Science Fiction Film Reader. New York: Limelight, 2004, pp. 5-12.

XAVIER, Ismail. A alegoria langiana e o monumental: a figura de Babel em Metropolis. In:

CAPELATO, Maria Helena, MORETTIN, Eduardo, NAPOLITANO, Marcos e SALIBA, Elias Thomé (orgs.). História e Cinema. São Paulo: Alameda, 2007, pp. 15-38. 